\title{
Systematic Literature Review of Convergence: A Systems Perspective and Re-evaluation of the Convergence Process
}

\author{
Anton Klarin, Yuliani Suseno, and Jennifer Ann L. Lajom
}

\begin{abstract}
This study examines convergence by providing a systematic literature review using scientometric method. Despite the steady growth of convergence literature, we still have an incomplete understanding of convergence concepts as well as the processes of industry convergence. Our systematic review highlights several key findings. First, our review highlights six clusters of research on convergence. Second, our analysis suggests that the process of convergence does not necessarily progress in the three- to four-step supply-side process as postulated in the literature, i.e., from scientific convergence, technology convergence, market convergence, and finally to industry convergence. Although existing literature suggests that industry convergence occurs as a result of supply-side convergence, we expand on this proposition and put forth market-driven convergence processes. Third, we provide a typology of the convergence concepts to bring clarity and avoid indiscriminate use of the various convergence concepts. Finally, our study offers new debates on the literature of convergence, providing scholars with research directions that extend beyond the standard convergence processes. Our systematic review is relevant to scholars and managers as the study highlights a taxonomy of convergence scholarship, a typology of convergence concepts, and a reevaluation of the industry convergence process model to drive the research forward.
\end{abstract}

Index Terms-Bibliometrics, convergence process, digital convergence, driving markets, industrial convergence, industry convergence, informetrics, market convergence, market-driven, media convergence, scientific convergence, scientometrics, systematic literature review, taxonomy, technological convergence, technology convergence, typology

\section{INTRODUCTION}

$\mathrm{C}$ ONVERGENCE is a complex phenomenon involving multiple layers and interactions of industries, firms, users, regulatory bodies, policy, technology, markets, and media. The existing literature on convergence is interdisciplinary but unfortunately, it is still fragmented. In fact, there currently exists some confusion in relation to different convergence concepts. For instance, industry and industrial convergence concepts have been used interchangeably in many studies although each has its origins, meanings, and propositions [1]-

Manuscript received August 30, 2020; revised March 06, 2021 and August 06, 2021; accepted October 08, 2021. Review of this article was arranged by Department Editor Francesco Appio, corresponding author: Anton Klarin.

Anton Klarin was with the School of Business and Law, Edith Cowan University, Joondalup, WA 6027 Australia. He is now with the Faculty of Business and Law, Curtin University, Bentley, WA 6102 Australia (e-mail: gklarin@gmail.com).
[5]. Where industry convergence (IC) refers to the blurring of industry boundaries, industrial convergence refers to the gradual convergence in industrialization levels (where for instance, developing countries are catching up to the developed world). Industrial convergence can also reflect the blurring of the boundaries between economies and geographical regions. Given the various concepts of convergence, unsurprisingly it remains ambiguous as to how the concepts of convergence are distinct from one another. Additionally, the literature on convergence has predominantly examined how convergence occurs, i.e., the processes that result in the convergence, with many of the studies focusing on examining a specific type of convergence which is IC. The term 'industry' here refers to the blurring and redefinition of boundaries between formerly distinct industries, by combining scientific knowledge, technology, and markets [1], [6]. Industry, in this sense, denotes "any grouping of firms which operate similar processes and could produce technically identical products within a given planning horizon $[\ldots]$ They encompass constraints on the input side as each firm would be using very similar inputs of labor, raw material and machinery" [7, p. 35]. Essentially, IC suggests the convergence of two or several separate industries, bringing together processes and products/services offered by these groups of firms [8]-[11].

Studies examining IC have been empirically demonstrated across a variety of industries including computers, telecommunications, semiconductors, and other electronic products [12], information technology-related industries [13], [14], information communication technology (ICT) [10], [15], [16], media [17], [18], tourism [19], [20], nutrition [8], [11], and robotics [21], [22]. Existing studies have thus far focused on the 'high degree science and technology driven' industries and sectors [10], [23], mostly reliant on patent data, i.e., technologyrelated data [23], where convergence is facilitated through the supply-side in a stepwise process, starting with scientific convergence (SC), followed by technology (TC) and/or market convergence (MC), culminating in industry convergence (IC). Interestingly, there have been limited studies exploring the

Yuliani Suseno is with the Newcastle Business School, University of Newcastle, Newcastle, NSW 2300 Australia (e-mail: yuli.suseno@newcastle.edu.au)

Jennifer Ann L. Lajom is with the School of Business and Law, Edith Cowan University, Joondalup, WA 6027 Australia (e-mail: j.lajom@ecu.edu.au). 
demand-side of IC [1], [6], [11], [23]. This is theoretically and practically important to explore given that such study contributes to our understanding of the different processes of convergence.

In addressing these gaps in the literature, the goal of this study is to not only differentiate the various concepts of convergence but also to specifically focus on IC, being perhaps the most researched convergence concept in the literature. The focus on IC is to enable us to examine this concept in-depth to move us forward in terms of our understanding of IC. Specifically, this study attempts to answer two research questions. The first research question is "What are the key research streams within convergence scholarship?" In answering this research question, we conducted a systematic review of the convergence scholarship using scientometric method to derive a taxonomy of the scholarship by identifying the disparate research streams on convergence. At the same time, our systematic review provides a typology of the convergence concepts to bring clarity to the different terminologies.

The second research question is related to examining the different processes of convergence. To further understand the processes of convergence, we explore the demand-side IC, or often referred to as market-driven convergence, whereby consumers often 'dictate' the market. Consequently, we frame the study to address the second research question of "What are the processes of market-driven industry convergence?"

This research contributes to the convergence literature and practice in several ways. First, we contribute to the literature by providing a taxonomy of the current convergence research to identify clusters of existing research on convergence. Although the convergence literature is interdisciplinary with diverse research streams including technology studies, economics, politics, development studies, media, geography, business disciplines, and others, interestingly there has been no study attempting to integrate the entire convergence literature into one taxonomy. Based on the largest review of studies examining convergence, we are in a unique position to offer systematized future research directions of this emerging and important scholarship. The systems view of convergence would particularly be beneficial to progress the existing research on convergence by identifying how the various disciplines in the field of study are structured and related to each other. In addition, bridging these disparate streams of research into one taxonomy of convergence enables us to identify existing research gaps and pertinent research directions to further develop the scholarship on convergence and provide value to practitioners.

Second, the study provides a systems view of convergence, enabling us to provide the key convergence concepts in one typology. Given that many existing studies on convergence have utilized various concepts interchangeably, this creates confusion in the identification, definitions, and meaning of convergence concepts. For example, industrial convergence in economics, geography, and development studies refers to the convergence towards similar levels of industrial productivity and output [2], [24]-[26], whereas more recent studies of convergence utilize the conceptually distinct industry convergence and industrial convergence interchangeably [23], [27], [28]. Our review to delineate these concepts aims to ensure clarity in defining and understanding various convergence concepts in the literature. Understandably, to ensure the application of convergence in practical real-world conditions, consistency in the concept identification, definitions, and systematization of the topic is critical and is needed for this emerging field of study.

Finally, we specifically contribute to the IC literature by demonstrating the need to further consider the implications of market-driven IC. We propose alternative IC processes that are not always reinforced by technology and follow the conventional linear process. Arguably, in industries where the market dictates products and services, managers can be more proactive to establish clear lines of communication and collaboration with consumers to retain competitiveness.

The paper is structured as follows. We first begin with an overview of the current literature on convergence. We then explain how we utilized scientometric method to carry out the systematic review of the literature. Third, we present the overarching interdisciplinary taxonomy of convergence scholarship, provide a typology of inter-related convergence concepts, and highlight the processes of market-driven convergence. Based on these contributions, we offer future research directions that will help bring clarity and consistency to this emergent interdisciplinary topic. The research directions will also provide an impetus for practitioners and academics to further consider the processes of convergence that are instructive to management and research in the long term. The structure of the study is demonstrated schematically in Figure 1.

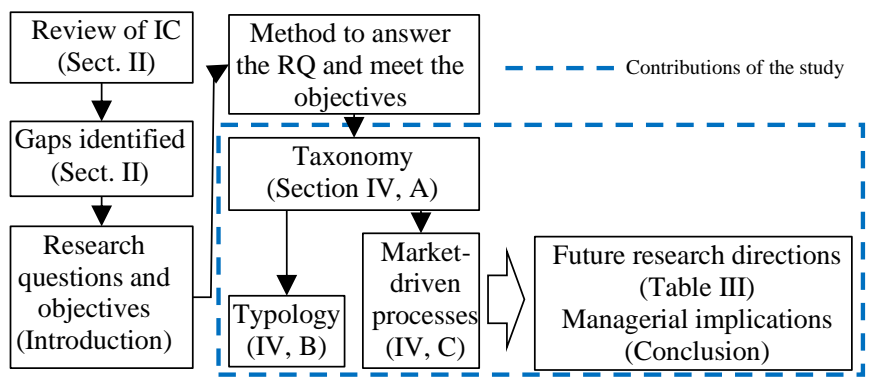

Fig. 1. Structure of the study

\section{II.LITERATURE ON CONVERGENCE}

Convergence has its roots in the concept of technological convergence, first proposed by Rosenberg [4, p. 423]. An earlier definition of technological convergence refers to the "industries which were apparently unrelated from the point of view of the nature and uses of the final product became very closely related (technologically convergent) on a technological basis." Rosenberg [22, p. 443] then questioned whether the concept of technological convergence occurred in other industries in the later years. This gave an impetus to the scholarship of technology convergence, although this terminology is used interchangeably with technological convergence in many studies on convergence (e.g. Kose and 
Sakata [22]). Despite the steady growth of the convergence literature, we still have an incomplete understanding of the convergence concepts. Thus, the interdisciplinary research of convergence requires a systematic and analytic review to provide clarity and avoid indiscriminate use of these different concepts.

Studies on convergence are underpinned by exploring how products and services enter the market, which can be explained through the concept of market orientation (MO). There are two approaches to MO - 'driving markets' and 'market-driven' which cater to the supply-side and demand-side convergence, respectively [29], [30]. The 'driving markets' approach, commonly known as the product-driven or supply-side approach, is where a product or service offering is created and introduced to the market; this approach is often heavily dependent on research and development (R\&D) for a breakthrough or a radically innovative product/service [31]. The introduction of new products/services generally follows the traditional multi-stage process of product development [32] involving $\mathrm{R} \& \mathrm{D}$, design, manufacturing, marketing, and sales, among other processes, which are not visible to the customer. The products are successful in the market when their 'performance' often exceeds the market demands [33] - and in this case, industry convergence would then occur.

Having empirically studied the cosmeceutical as well as nutraceutical and functional food industries through patent analysis, Curran and colleagues [1], [10] demonstrated that convergence is a sequential process consisting of four steps scientific (SC), technology (TC), market (MC), and industry convergence (IC). This can be illustrated by way of engagement of the scientific disciplines in cross-disciplinary research and collaborative research as the first step of convergence. In the second step, TC occurs when scientific research is applied to technology development. The third step is illustrated by product-market combinations where consumers use the newly created hybrid products [34]. In the fourth step, firms then begin to converge where "the full industry convergence will only take place when technologies and markets converge" [1, p. 386]. Since the seminal studies by Curran and colleagues [1], [10], other empirical studies have also supported the findings of the four-step process in various technology-related product industries [6], [9], [23], [28], traditionally driven by technology-push from SC, TC, MC, and finally to IC.

However, there is scope for further exploration of convergence processes in other industries where the demandpull condition is predominant. The market-driven or the demand-side approach prescribes using market research to first gauge customer needs and then develop offerings based on the research findings. Most incremental/sustaining innovation products and services are generally market-driven [30]. When examining the market-driven model of convergence, interestingly both $\mathrm{MC}$ and IC can occur without the necessary prior sequence of convergence in scientific interdisciplinary collaboration. In other words, the process of convergence does not prescribe to the process of SC, TC, MC, and IC. In fact, quite often, the market-driven approach 'avoids' scientific convergence in the application of $\mathrm{R} \& \mathrm{D}$ of products before an industry converges. For example, some studies on convergence are reliant on gathering data from Wikipedia [5] and newspaper articles of US-listed firms [9]; these studies do not exactly reflect the supply-side convergence process commonly noted by scholars such as Curran et al. [1], [10]. Similarly, the telemedicine and telehealth industries that are worth US\$1.25 trillion do not typically follow the supply-side convergence. These industries converge as a result of the confluence of two or more industries and market demands [35], but not the convergence of scientific products. As such, the process of convergence does not always follow the dominant sequential process model proposed by Curran et al. [1], [10].

When examining the processes of convergence, the outcome of such processes is the convergence of the industries, i.e., industry convergence (IC). As such, studies exploring the processes of convergence are related to IC. Interestingly, while the literature depicts the existence of market-driven convergence, there have been limited studies that propose or describe the processes of market-driven convergence so far, except for a simplified explanation of MC leading directly to IC [8], [23]. There is a need to examine whether industry convergence evolves "when scientific disciplines, technologies and markets have converged" [1, p. 386] or whether industry convergence may "only take place when technologies and markets converge" [1, p. 386]. Given this contention, we not only provide a taxonomy of convergence scholarship and a typology of the convergence concepts, but also explore the processes of IC in this study.

\section{METHOD}

To provide a thorough review of a topic, it is often insufficient to engage in a traditional narrative review of the literature [36], [37], and we thus adopt a systematic review of the literature. In particular, systematic reviews using scientometrics are increasingly common in providing comprehensive, reliable evidence-based publications [38]. Scientometric reviews rely on semantic algorithms that aim to objectively analyze the available data to provide reliable findings synthesized from the body of literature. Scientometric reviews in fact go beyond traditional reviews by providing science mapping that allows a holistic visualization of a particular research domain. This is especially pertinent in areas where there are significant gaps between scientific disciplines. Creating maps based on a complete scholarship of a research domain arguably provides a holistic understanding of the topic that bridges these diverse scientific disciplines.

Scholars from various disciplines may then utilize science maps to overcome the boundaries between scientific domains and create value through collaboration in knowledge advancement [39]. The scientometric review enables us to systematize existing research studies on convergence into several inter-related clusters. We utilize VOSviewer clustering software in order to identify relevant convergence terms used in the literature and their 'positions' on the map. The software enables clustering by assigning nodes in a network based on relationships between the terms. Publications that are assigned to the same clusters are likely to have a theme in common 
(Korom [40] and van Eck and Waltman [41], [42]). As such, this algorithmic clustering enables the delineation of conceptual constructs and the analysis of all published research on the topic in one visual map [31], [43].

The scientometric review adopted in this study follows the guidelines of systematic reviews in the social sciences framework as proposed by Petticrew and Roberts [36]. We also followed the guidelines for a systematic review in other studies, including those by Tranfield et al. [37], Mulrow [44], and Grant and Booth [45]. The method in conducting our systematic review is as follows. First, we set out the research questions building on the findings of our preliminary scoping review that allowed us to gain an initial understanding of the IC literature. In the second stage, we considered the types of publications and included all publication types - book chapters, books, conference proceedings, editorials, research notes, and research letters on the topic, to gain a systems and holistic view of the convergence literature [42], [46].

Third, in order to carry out a comprehensive literature search, we utilized the Web of Science (WoS) database as it is considered one of the largest scientific knowledge databases [47], [48]. The WoS also has major overlaps with Scopus, and as such, there will be marginal divergences between the two databases, particularly as we compare large volumes of publications [49]. The dates of the document search were set from the beginning of the WoS listing to 19 December 2019. We searched for ""scien* convergence" OR "techn* convergence" OR "market* convergence" OR "industr* convergence"" as the four types of convergence offered by Curran et al. [1], [10] and similar studies. The search results garnered 861 studies from the WoS.

In the fourth step, we carefully went through the titles, abstracts, and keywords of all 861 studies. There were 17 studies that had no relevance to our research topic and as such, they were not included as part of our dataset. We further excluded 9 studies that contained the search string but these articles had no relevance to IC. There were also 3 duplicate studies that were present in the WoS dataset, which were then excluded from our final dataset.

In the fifth step, we then compared our dataset obtained from the WoS with the same search string results from Scopus. We also did a keyword search on Google Scholar to further identify other publications and found 25 publications that were not originally found in the WoS dataset. For example, there were several publications in a journal that does not have an impact factor. Given that a journal with no impact factor is not covered by the WoS database, we might have missed out on several other articles if we did not search beyond the WoS. These additional publications are then included as part of our dataset. Figure 2 demonstrates the search selection process and the results included in the study, with 857 documents as part of our dataset.

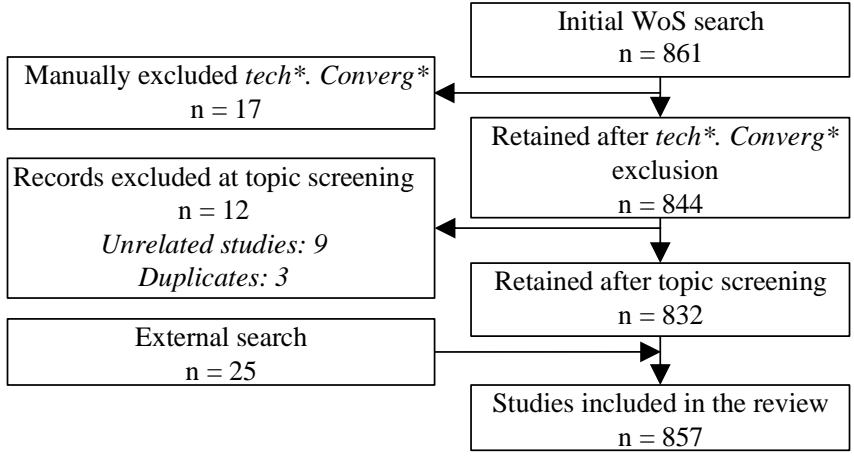

Fig. 2. Results of the search and study selection criteria

Finally, we used the VOSviewer, an innovative science mapping software, to evaluate and map existing research on this topic of IC. The software utilizes citation analysis that demonstrates relationships between scientometric indicators (including authors, organizations, and terms) in a visual map [50]. The VOSviewer software automatically identifies (1) the most frequently used terms within a body of text, and (2) the relationships between these terms. Consequently, this approach systematically reveals the key themes within the IC paradigm by using a number of terms from the text (thematic analysis). This approach also visually demonstrates how themes are linked with each other based on the frequency and occurrence of terms within the contexts (semantic analysis).

In generating the mapping reviews, the default settings of the software, which generally represent best practices in conducting scientometric mapping, were utilized [41], [51]. Noun phrases that occur in at least 5 different documents were extracted. Based on the entire dataset on IC (857 documents), the mapping then categorized the terms according to the clusters. Terms that are strongly associated with each other are automatically placed in the same cluster. In this way, the clustering of the convergence terms demonstrates the mapping of the existing literature of IC.

\section{FINDINGS AND Discussion}

In this study, the software produced a taxonomy of the existing convergence scholarship by identifying the disparate research streams on convergence. The mapping from a dataset of 857 publications resulted in six major clusters of convergence scholarship. From this dataset of publications, we were also able to identify the key themes in each cluster and label the clusters accordingly.

The six clusters as the taxonomy of convergence are represented as the: (i) red cluster - industry convergence, (ii) green cluster - media and communication convergence, (iii) blue cluster - market, club, and cluster convergence, (iv) yellow cluster - the impact of convergence on learning and development, (v) lilac cluster - industrial convergence, and (vi) aqua cluster - regulatory oversight and user adoption. To provide a thorough investigation of the areas of convergence research, each of these clusters is analyzed according to the themes within each cluster. The results of the thematic analysis are represented visually in Figure 3. In the map, the frequency of occurrences is represented by the size of the noun phrase, i.e., 
larger circles represent a higher number of occurrences of the term.

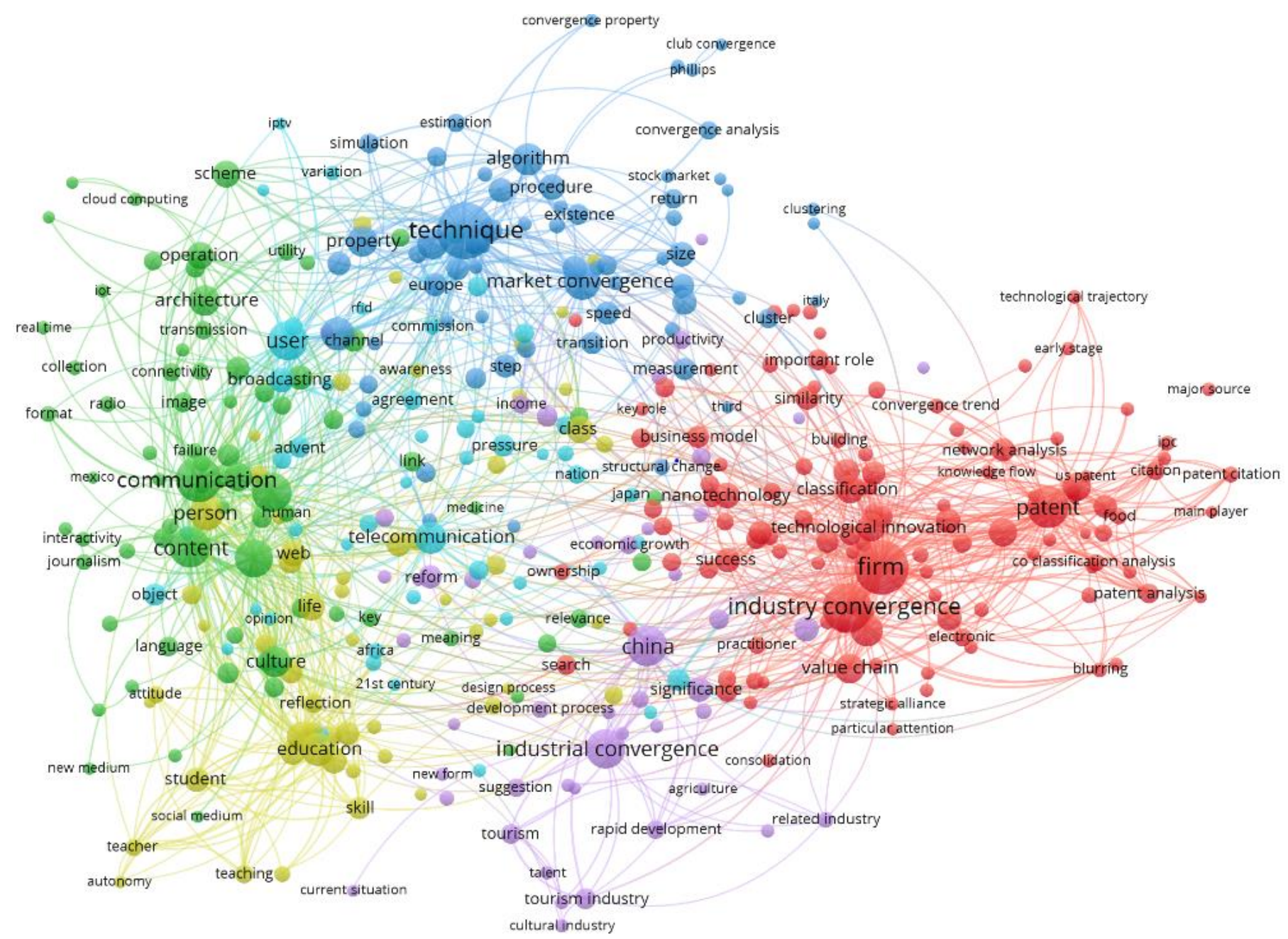

Fig. 3. The scientometric mapping of industry convergence scholarship

In addition to providing a visual representation of the IC taxonomy as shown in Figure 3, several tables to highlight the bibliometric (descriptive citation information), thematic, and semantic results extracted from the scientometric review of the topic are provided. Table I demonstrates: i) the terms that are prevalent in the documents that receive the highest citation counts, ii) the terms that appear in the articles with the most recent publication date, and iii) the indicative disciplinary domains of convergence.

TABLE I

KEY TERMS DisCUSSED IN THE SIX RESEARCH STREAMS

\begin{tabular}{llll}
\hline \multicolumn{1}{c}{ Top article citation impact terms ${ }^{\mathbf{a}}$} & \multicolumn{1}{c}{ Top trending terms $^{\mathbf{b}}$} & Indicative fields \\
\hline & Functional food; chemical; & Patent information; network analysis; & \\
& pharmaceutical industry; phytosterol; & knowledge flow; decision maker; & \\
& blurring; origin; partner; location; & category; dynamic pattern; ICT & \\
& practitioner; strategic alliance; food; & convergence; Korea Intellectual & Management; \\
Red- Industry & knowledge flow; alliance; scholar; & Property Office; knowledge diffusion; Engineering; \\
convergence & technological trajectory; dynamic pattern; & technology field; centrality; US patent; Scientometrics \\
& competence; patent; international patent & cooperation; international patent & \\
& classification; overlap; patent & classification; patent citation analysis; & \\
& information; fusion; ICT industry; & indicator; patent data & \\
& electronic; bio; open innovation & & \\
\hline
\end{tabular}




\begin{tabular}{|c|c|c|c|}
\hline $\begin{array}{l}\text { Green - Media } \\
\text { and } \\
\text { communication } \\
\text { convergence }\end{array}$ & $\begin{array}{l}\text { Journalism; news; social network; } \\
\text { utility; human; threat; multimedia; } \\
\text { notion; mobile device; medicine; } \\
\text { frequency; internet; IoT; rapid } \\
\text { technological convergence; digitization; } \\
\text { channel; media convergence; sensor; } \\
\text { cloud computing; transmission; } \\
\text { journalist; scheme; computing; } \\
\text { digitalization }\end{array}$ & $\begin{array}{l}\text { IoT; collection; journalist; real time; } \\
\text { majority; digitalization; new medium; } \\
\text { cloud computing; meaning; utility; } \\
\text { human being; convergent technology; } \\
\text { Mexico; threat; new era; journalism; } \\
\text { monitoring; text; sensor; frequency; } \\
\text { Latin America; operation; image; } \\
\text { constraint }\end{array}$ & $\begin{array}{l}\text { Media studies and } \\
\text { journalism; } \\
\text { Management; } \\
\text { Engineering }\end{array}$ \\
\hline $\begin{array}{l}\text { Blue - Market, } \\
\text { club, and cluster } \\
\text { convergence }\end{array}$ & $\begin{array}{l}\text { Marketplace; parameter; Germany; } \\
\text { cluster; examination; agent; neural } \\
\text { network; France; industry level; pricing; } \\
\text { distance; movement; divergence; } \\
\text { convergence property; accuracy; new } \\
\text { approach; estimation; structural change; } \\
\text { property; procedure; Italy; output; return }\end{array}$ & $\begin{array}{l}\text { Clustering; Phillips and Sul; France; } \\
\text { industry level; movement; input; } \\
\text { investor; Germany; examination; size; } \\
\text { applicability; cluster; stock market; } \\
\text { respect; measurement; benchmark; test; } \\
\text { accuracy; transition; efficiency; price; } \\
\text { club convergence; Italy }\end{array}$ & $\begin{array}{l}\text { Economics; } \\
\text { Politics; } \\
\text { Governance; } \\
\text { Engineering; } \\
\text { Computing; } \\
\text { Finance; Culture }\end{array}$ \\
\hline $\begin{array}{l}\text { Yellow - The } \\
\text { impact of } \\
\text { convergence on } \\
\text { learning and } \\
\text { development }\end{array}$ & $\begin{array}{l}\text { Stability; competency; life; observation; } \\
\text { recognition; motivation; class; person; } \\
\text { confluence; awareness; task; } \\
\text { professional; humanity; learning; reality; } \\
\text { skill; Spain; balance; functioning; } \\
\text { tension; attitude; flexibility; reflection; } \\
\text { safety; learning process; participation; } \\
\text { education; description; ICTs }\end{array}$ & $\begin{array}{l}\text { School; smartphone; humanity; } \\
\text { accordance; learning process; person; } \\
\text { training; reflection; description; life; } \\
\text { awareness; balance; student; ontology; } \\
\text { design process; ability; motivation; } \\
\text { ICTs; safety; teacher; confluence; art; } \\
\text { teaching; reality; construction; attitude; } \\
\text { autonomy; education }\end{array}$ & $\begin{array}{l}\text { Education; } \\
\text { Management; } \\
\text { Psychology }\end{array}$ \\
\hline $\begin{array}{l}\text { Lilac- } \\
\text { Industrial } \\
\text { convergence }\end{array}$ & $\begin{array}{l}\text { Productivity; imitation; technology } \\
\text { transfer; sustainable development; India; } \\
\text { synergy; capital; contradiction; industry } \\
\text { structure; manufacturing industry; } \\
\text { foundation; current situation; economic } \\
\text { growth; adjustment; next generation }\end{array}$ & $\begin{array}{l}\text { Industrial integration; cultural industry; } \\
\text { tourism industry; sustainable } \\
\text { development; exploration; current } \\
\text { situation; talent; rapid development; } \\
\text { related industry; tourism; industrial } \\
\text { development }\end{array}$ & $\begin{array}{l}\text { Economics; } \\
\text { Policy; } \\
\text { Operations } \\
\text { management }\end{array}$ \\
\hline $\begin{array}{l}\text { Aqua - } \\
\text { Regulatory } \\
\text { oversight and } \\
\text { user adoption }\end{array}$ & $\begin{array}{l}\text { Academia; usefulness; Africa; } \\
\text { formulation; mobile phone; variation; } \\
\text { deregulation; effectiveness; trade; } \\
\text { association; interpretation; Japan; } \\
\text { pressure; governance; ministry; Fourth } \\
\text { industrial revolution; Australia; } \\
\text { establishment; new way }\end{array}$ & $\begin{array}{l}\text { Fourth industrial revolution; difficulty; } \\
21 \text { st century; opinion; key component; } \\
\text { technology adoption; IPTV; thought; } \\
\text { formulation; effectiveness; usefulness; } \\
\text { wide range; Africa; mobile phone; } \\
\text { academia; RFID; reference; nation; } \\
\text { new way }\end{array}$ & $\begin{array}{l}\text { Marketing; Law; } \\
\text { Policy; } \\
\text { Governance; } \\
\text { Management }\end{array}$ \\
\hline
\end{tabular}

a Top impact terms appear in the highest average normalized citation articles, arranged in descending order.

${ }^{\mathrm{b}}$ Top trending terms appear in the most recent articles, arranged from the most recent publication date.

\section{A. The taxonomy of convergence scholarship}

\section{1) Red cluster: Industry convergence}

This cluster discusses convergence from the current dominant stepwise perspective of IC as offered by authors such as Bröring et al. [8], Curran et al. [1], Sick et al. [6], and others. Research within this cluster adopts IC from the perspective of the "blurring of boundaries between two or more industries" $[10$, p. 258]. The highly occurrent terms related to the established IC methodologies are reflected in this cluster, and these terms include patent, patent data, patent analysis, citation, co-classification analysis, as well as research industries and technologies including ICT (industry/convergence), biotechnology, technological field, nanotechnology, electronics industry, chemical, functional food, pharmaceutical industry, and others [11], [28], [52], [53]. Only two countries emerge as the top occurrences in this cluster - the USA and South Korea, indicating that large proportions of data are mainly from these countries.

\section{2) Green cluster: Media and communication convergence}

The overarching theme within the green cluster is communication technology convergence, covering topics related to media convergence and the communication industry developments. The rise of internet technologies certainly leads to the displacement of earlier production and consumption practices in the media and the general communication industry(ies) and patterns that led to convergence. Specifically, one theme in this cluster is the "technical convergence of media platforms (which) refers to the merging of various platforms such as TVs and PCs into a multi-functional media platform; that is, the functions of formerly quite different applications are being brought together, leading to a greater range of choice of content." [54, p. 491]. For example, studies including Christin [55], Humphreys et al. [56], Westlund [17] emphasize the increasing role of digital content over the traditional paperbased models in all industries, leading to the convergence in digitalization. As another example, the work by Flanagin [57] 
describes how technological advancements caused inevitable dramatic changes in the media and interpersonal communication.

The green cluster therefore illustrates the study of technical convergence in communication as well as its implications on media convergence. This extends the study of the IC process scholarship as proposed by studies including Bröring et al. [8], Curran et al. [1], and Song et al. [53] in the context of the telecommunications industry.

\section{3) Blue cluster: Market, club, and cluster convergence}

The blue cluster essentially illustrates the aspects of political, economic, technological, and social differences among markets or countries, noting that such differences will decrease as industries move toward the 'uniformity' of 'pluralistic industrialism' [58, pp. 288-296]. The 'pluralistic industrialism' is a feature of the 'convergence theory' that stipulates that the diminishing returns to investment cause the growth rate of a country (or a market) to decline, i.e. the richer economies grow slower than the poorer economies, which eventually leads to economic convergence [59]. Another relevant theme within the market convergence uses Phillips and Sul's [60] econometric analysis, which is particularly useful for assessing the convergence of stock markets across the globe [61]-[64].

From market convergence, a stream of literature investigating 'club convergence' [3], [60] and 'cluster convergence' [27], [65] emerged. The club and cluster convergence are related to the 'steady' state of economic development that is dependent on the income per worker (GDP per worker) and the structural characteristics of an economy. Countries are grouped in different clusters depending on the income per capita and the structural set-up of the country [66], leading to a long-term convergence of clusters.

Rosenberg's [4] identification of 'technological convergence', which is traditionally embedded within the wider 'theory of convergence' [4, p. 415], is also highlighted within this cluster.

4) Yellow cluster: The impact of convergence on learning and development

The yellow cluster is almost entirely dedicated to the effects of convergence on human development, particularly focusing on technological convergence (TC). Most studies that are grouped within this cluster investigate the implications of TC on education, youth, and learning. For example, Yen and Abdous [67] demonstrate that faculty engagement plays a crucial role in effective teaching and learning outcomes regardless of the delivery modes and convergent technologies that have disrupted traditional classroom delivery. As another example, in an informative study of the antecedents and implications of TV binge-watching, Vaterlaus et al. [68] suggest that TV binge-watching is largely the result of technological convergence. Hernández-Merayo et al. [69] further explore the experiences of young adults participating in the political community and constitutional order enabled by technological convergence, with such platforms allowing communication, discussion, and the building of shared collective development in today's learning environment.

Karakas and Manisaligil [70] demonstrate that virtual collaboration, global connectivity, online communities, and digital creativity change the landscape of workplace learning in the creative digital era, leading to technological convergence in the way we learn. Thornhill-Miller and Dupont [71] also highlight technological convergence through the use of virtual reality and other technologies in facilitating improved human performance. As a final example, Fainholc [72] describes how decentralization, personalization, increased flexibility, and other effects of telematic networks lead to convergence in the learning environments and teaching systems. All these examples suggest an impact of convergence on learning and development.

\section{5) Lilac cluster: Industrial convergence}

The lilac cluster is based around discussions of economic development through industrialization. This cluster is essentially about industrial convergence which is different from the red cluster on industry convergence. The terms in the lilac cluster (as shown in Table I) include industrial convergence, competitiveness, reform, economic growth, manufacturing industry, productivity, development process, among others. This cluster is further based on the political and economic discourse that emerges from societal and national level economic convergence.

Within this cluster, industrial convergence is mainly illustrated as the impact of convergence on productivity growth. For example, Cameron et al. [73] demonstrate that technological convergence was statistically significant on the rates of productivity growth at the industry-level in the United Kingdom since 1970. Dowrick [74] highlights that countries converge at an average rate of approximately $3.5 \%$ annually, highlighting the focus on industrial convergence. Interestingly, Arrighi et al. [25] empirically contradict the theory of convergence by demonstrating that industrial convergence has not been accompanied by a convergence in the levels of income and wealth enjoyed by the residents of the former First and Third Worlds. This is primarily due to the fact that the innovators (the developed countries) maintain oligarchic wealth that perpetuates the 'virtuous circle' of high incomes and innovations in the developed countries, thereby maintaining the gap between the First and Third Worlds. Arguably, industrial convergence is a moving target that grows at different rates in each country [66], and the lilac cluster emphasizes the various publications on this aspect of industrial convergence.

\section{6) Aqua cluster: Regulatory oversight and user adoption}

This cluster illustrates the regulatory oversight, governance of convergence, and user implications of technological convergence. The governance or regulatory oversight is primarily concerned with national-level policies regarding technological convergence and its consequences on economic development [75]-[77]. For example, Yasunaga et al. [78] hypothesize that technology roadmaps proposed by governments are powerful tools to not only guide private and public organizations to create new business models but also to promote measures for different technologies to converge. In relation to the governance of convergence, McLeish and Nightingale [79] also discuss and provide suggestions on the convergence of the dual use of legitimate scientific discoveries 
as weapons while ensuring a balance between social costs and security restrictions.

Other themes grouped within the aqua cluster illustrate the users' consumption patterns and attitudes toward technologically convergent products and services [80]-[83]. For example, Han et al. [84] demonstrate that consumers in general prefer convergent products although these products may not necessarily be technologically advanced. However, as technological sophistication increases, consumers are more likely to prefer specialized options. Humphreys et al. [56] further confirm technological convergence in the case of internet users, where they prefer a particular technology, i.e., computers, for an immersive internet experience. As another example, Shin [85] highlights that customers are open to new convergent technologies such as the Internet Protocol Television, if there is a perception of value and product attributes such as stability, convenience, and usefulness. Arruda-Filho et al. [86] further highlight that the majority of consumers who are innovative are more likely to utilize convergent technologies such as smartphones for functionality and utilitarian reasons. The green cluster thus demonstrates user adoption, including their consumption behavior and patterns.

\section{B. A typology of convergence concepts}

The findings of prior studies on convergence cannot provide a holistic perspective given that there are many concepts that are often used interchangeably. A large number of studies have used industry and industrial convergences interchangeably, and many also do not distinguish between technology and technological convergences. Our research into the large convergence-related literature dataset of 857 publications reveals that these concepts are different based on the context within which the terms are utilized. Our analysis highlights that industry convergence broadly refers to the blurring of boundaries between industries, but industrial convergence, on the other hand, refers to the convergence of industrialization in a country or region. At the same time, there are distinct differences between technology and technological convergences where technology convergence is about new technological combinations as in products and/or services, and technological convergence refers to a process by which different industries come to share similar technological bases. Table II presents a typology of the convergence concepts.

TABLE II

TYPOLOGY OF COMMON CONVERGENCE CONCEPTS

\begin{tabular}{|c|c|c|}
\hline Cluster & Concept & Indicative definition \\
\hline \multirow{4}{*}{$\begin{array}{l}\text { Red - Industry } \\
\text { convergence }\end{array}$} & $\begin{array}{l}\text { Industry } \\
\text { convergence }\end{array}$ & $\begin{array}{l}\text { "“blurring' of boundaries between industries, induced by converging value propositions, } \\
\text { technologies and markets" (Bröring et al., 2006, p. 488). }\end{array}$ \\
\hline & $\begin{array}{l}\text { Knowledge } \\
\text { convergence }\end{array}$ & $\begin{array}{l}\text { "the emergence of serendipitous coevolutionary spill-over between previously unassociated } \\
\text { and distinct knowledge bases, giving rise to the erosion of established boundaries that } \\
\text { isolate industry-specific knowledge" (Hacklin et al., 2009, p. 725). }\end{array}$ \\
\hline & $\begin{array}{l}\text { Applicational } \\
\text { convergence }\end{array}$ & $\begin{array}{l}\text { "the transition of technological convergence into opportunities for new value creation in } \\
\text { such a way, that it with respect to the majority of metrics outperforms the sum of the } \\
\text { original parts" [16, p. } 727] \text {. }\end{array}$ \\
\hline & $\begin{array}{l}\text { Digital } \\
\text { convergence }\end{array}$ & $\begin{array}{l}\text { "the unification of functions - the coming together of previously distinct products which } \\
\text { employ digital technologies" [87, p. 33]. }\end{array}$ \\
\hline
\end{tabular}

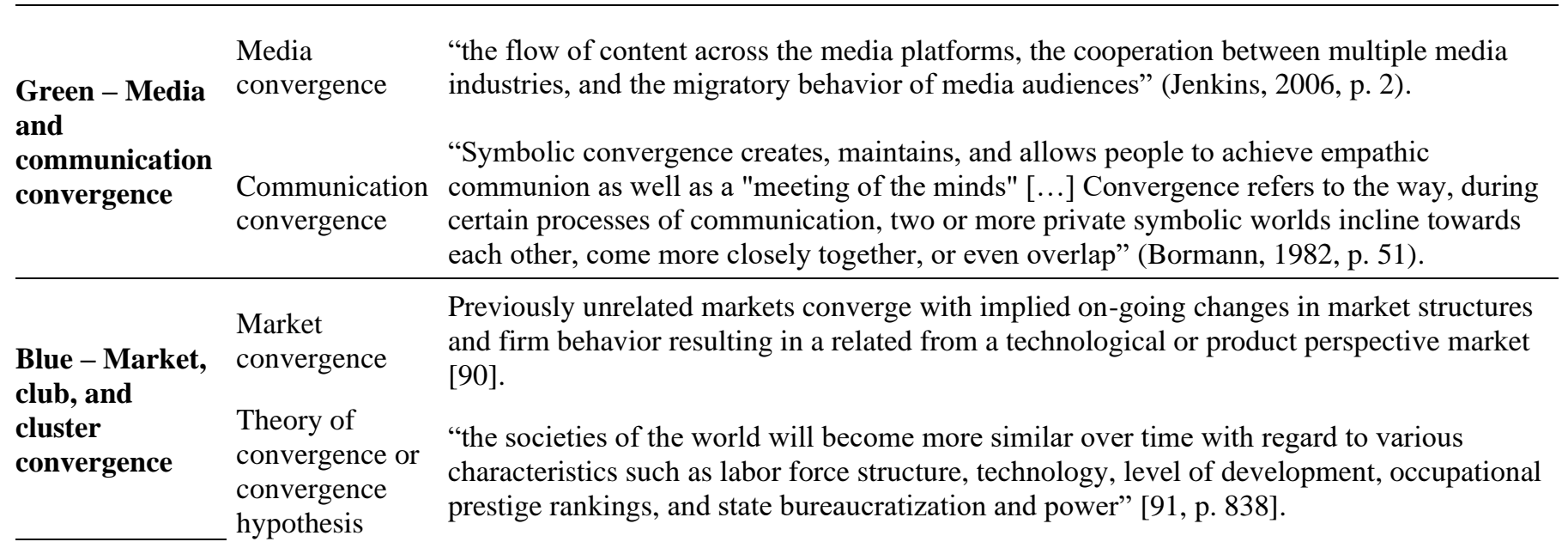


Classical convergence

"[...] diminishing returns to investment cause the growth rate of a country to decline as it approaches its steady state level of capital per unit of effective labour-implying that, ceteris paribus, richer economies grow slower than poorer economies" [74, p. 369].

Club/cluster " $[\ldots]$ the tendency of output per capita across countries to converge to multi steady-state convergence equilibria, one for each basin of attraction" [92, p. 47].

\begin{tabular}{|c|c|c|}
\hline $\begin{array}{l}\text { Yellow - The } \\
\text { impact of } \\
\text { convergence on } \\
\text { learning and } \\
\text { development }\end{array}$ & $\begin{array}{l}\text { Telematic } \\
\text { convergence }\end{array}$ & $\begin{array}{l}\text { Convergence of telecommunications and informatics to broadly describe the integrated use } \\
\text { of communications and information technology to transmit, store and receive information } \\
\text { from telecommunications devices to remote objects over a network, see Fainholc (2008). }\end{array}$ \\
\hline \multirow{3}{*}{$\begin{array}{l}\text { Lilac - } \\
\text { Industrial } \\
\text { convergence }\end{array}$} & $\begin{array}{l}\text { Industrial } \\
\text { convergence }\end{array}$ & Convergence in country or region industrialization levels, see Arrighi et al. (2003). \\
\hline & $\begin{array}{l}\text { Technological } \\
\text { convergence }\end{array}$ & A process by which different industries come to share similar technological bases [4]. \\
\hline & $\begin{array}{l}\text { Industrial } \\
\text { divergence }\end{array}$ & $\begin{array}{l}\text { A growing inequality in industrial development and its consequences between countries } \\
\text { and/or regions [3], [25]. }\end{array}$ \\
\hline \multirow{2}{*}{$\begin{array}{l}\text { Aqua - } \\
\text { Regulatory } \\
\text { oversight and } \\
\text { user adoption }\end{array}$} & $\begin{array}{l}\text { Regulatory } \\
\text { convergence }\end{array}$ & "the greater convergence of laws and regulations" [93, p. 48]. \\
\hline & $\begin{array}{l}\text { Convergence } \\
\text { product }\end{array}$ & $\begin{array}{l}\text { "digital-platform product bundle that physically integrates two or more digital-platform } \\
\text { technologies into a common product form (e.g., a mobile phone and a digital camera into a } \\
\text { camera phone)" (Han et al., 2009, p. 97). }\end{array}$ \\
\hline
\end{tabular}

\section{Market-driven convergence}

The taxonomy of the IC scholarship presented in the previous six clusters illustrates convergence based on 'driving markets'. This is particularly evident in the red cluster where the convergence is based on product-, organization-, and industrylevel convergence cases. We also found that some convergence processes could not be explained by the currently adopted processes proposed by Curran et al. [1], [10]. For example, when we examined the green cluster that is related to media convergence, we found that media giants like CBS carried out market research first instead of conducting scientific developments in research centers as the first step. These market insights were then translated to technology convergence, market convergence, and finally leading to IC [94]. Consequently, IC may not follow the conventional linear process of convergence. We therefore propose two alternative processes that were evident from our analysis of the convergence literature.

\section{1) Proposition 1: $M O \rightarrow T C \rightarrow M C \rightarrow I C^{l}$}

This proposition of process follows the traditional model of convergence offered by studies including Curran et al. [1], however in this convergence process, the process does not begin with scientific convergence. In the service industries, for example, the rise of digitization redefines convergence [95][98] where the process begins with no specific laboratorydependent scientific breakthroughs. In these industries, the process of convergence lacks the 'scientific convergence' where "distinct scientific disciplines begin to cite each other and collaborate", indicated through 'scientific publications' [6, p. 50].

Specifically, in relation to market-driven convergence, organizations often first identify their customer needs and technological trends, i.e., they start with market orientation (MO). This is then followed by carrying out research and development (technology convergence) in order to develop novel product offerings that lead to market convergence. In the long term, this process leads other companies following such market orientation, leading to $\mathrm{TC}$, then to $\mathrm{MC}$, and ultimately results in IC.

For example, Pool [94, pp. 23-55], using the examples of corporations, notes the process of convergence from MO. Some large companies including AT\&T were driven by customer needs and technological advancements to get involved in the convergence of telephone and radio. CBS, as another example, was involved in the convergence of print and electronics. These organizations were engaged in acquisitions and in-house investments to create media technology convergence and the ensuing market convergence [99]. This process highlights that in certain industries like service industries or others that do not necessarily depend on technological and capital prowess, MO can displace scientific convergence. MO then drives patents and market convergence in the form of new product/service offerings and subsequently enables these industries to converge.

2) Proposition 2: $M O \rightarrow M C \rightarrow T C \rightarrow I C$

This proposed process suggests that the process of IC is

\footnotetext{
${ }^{1}$ Market orientation $(\mathrm{MO}) \rightarrow$ technology convergence $(\mathrm{TC}) \rightarrow$ market convergence (MC) $\rightarrow$ industry convergence (IC)
} 
dictated by the market. In market-driven convergence, companies recognize that their consumers' needs or desires can bring about opportunities for market convergence. The process then transitions to $\mathrm{TC}$ where companies adopt and combine their technological knowledge from inside and outside of the boundaries of the firm. As an example, open-source application innovations such as the App Store and Google Play are platforms that are increasingly used (i.e. converged) by people and for people. This is the epitome of products/services developed by the market. Some of these applications, however, do have patents (for example, Facebook with its multitude of patents), and they then result in some level of technological convergence. As another example, Instagram not only facilitates the convergence of markets but also enables the convergence of technology. The company does this by adding other features to its photo and video management, for instance by adding messaging, stories, and website profiling. Instagram also facilitates the convergence of MC to TC by creating IGTV, enabling co-watching, and building on Instagram Reels which is a new way of creating and recording short, entertaining video clips.

The proposition further highlights a convergence of the industry through the process of MO, followed by MC and TC. An example to illustrate this proposition is the carsharing services. Given the often substantial amount of investment in purchasing and owning a vehicle, there is an increasing demand for carsharing services [100], [101]. This then makes such sharing activity become common, with an increasing number of firms offering similar services and users having plenty of options to choose from. This illustrates market convergence where the concept of individuals 'owning' a particular vehicle for a certain period of time is very much accepted. The increasing acceptance of carsharing services potentially creates convergence in the technology where the platform sharing capability is significantly enhanced over time. Arguably, even though the carsharing services present a new era in mobility, it is a lucrative market, attracting competitors and players into the market, thereby leading to IC.

To summarize, we propose two models of the market-driven convergence process - the first proposed process of convergence begins with TC, and the other proposed process begins with MC (see Figure 4). We do not, however, contend that there are only these two alternative convergence processes, but what we propose is a re-evaluation of the most prevalent model of IC as commonly highlighted in existing studies. We essentially present alternative processes to the current view of the IC process which is commonly depicted as a 'driving markets' linear process.

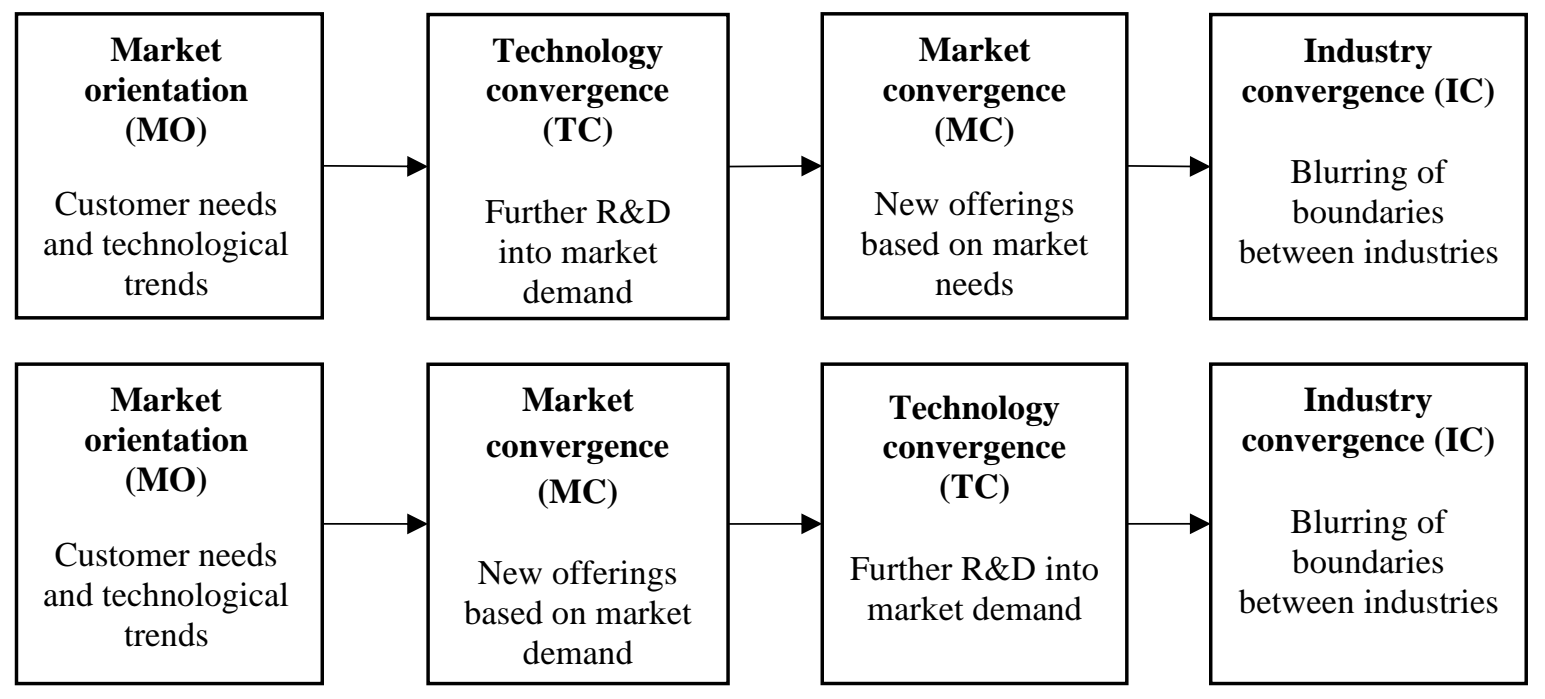

Fig. 4. Market-driven convergence processes

\section{CONCLUSION AND FUTURE RESEARCH DIRECTIONS}

By conducting a scientometric review into convergence and its processes as depicted in the literature (including [1], [6], [8], [10] and other studies), this study provides theoretical and practical implications in deepening our understanding of convergence. First, we provide a systems view of the entire convergence scholarship and identify six major clusters of research. Given that existing studies on convergence are not constrained within specific fields of studies, it is important for a review to be as comprehensive as possible by analyzing the entire scholarship of convergence. Second, we demonstrate several convergence concepts (see Table II to bring clarity and avoid indiscriminate use of the various convergence concepts).
Our attempt to provide a typology of convergence concepts (Table II) and provide a taxonomy of convergence research clusters (Section IV) enables us to truly engage in the 'blurring of boundaries' of convergence research streams and the identification of the key concepts of convergence for clarification and consistency.

Third, in relation to the most researched convergence concept in the literature - IC, we contend that there are alternative processes of IC. While the four convergence processes as described by Curran et al. [1] are commonly depicted in the literature, there are also studies and evidence to suggest that there are alternative processes of convergence. Based on our systematic review, we proposed the $\mathrm{MO} \rightarrow \mathrm{TC} \rightarrow \mathrm{MC} \rightarrow \mathrm{IC}$ 
and $\mathrm{MO} \rightarrow \mathrm{MC} \rightarrow \mathrm{TC} \rightarrow \mathrm{IC}$ pathways. These propositions are yet to be investigated quantitatively using large sets of data and further pathways can also be empirically tested in future studies.

The study offers practitioners, managers, or those that are interested in convergence an interesting overview of convergence while also providing clarity in understanding the concepts of convergence and the contextual domains within which these concepts are utilized. For example, policy-oriented practitioners will find club, market, industrial, and the theory of convergence explanations useful in crafting out contextual/market-appropriate policies that maximize the outcomes brought about by convergence. Technology-oriented practitioners can find practical suggestions and ideas based on the differences between industry convergence, technology convergence, and digital convergence in their innovative endeavors to cater to market needs and wants. Further, technology-oriented practitioners can consider the implications of market-driven convergence that is focused on customerdriven demand and close cooperation between the suppliers of these goods and services and the users, to drive convergence within their respective industries, technologies, or products/services. Therefore, there is a strong argument for managers to push forward the change in creating convergence. They can be more proactive by becoming the change agents themselves. Listening to the customers and taking a proactive stance thus becomes the first step towards convergence, signifying a potential paradigm shift away from the sole need for scientific developments that lead to convergence.

Based on the comprehensive scientometric review and conceptualization, we propose a number of future research directions organized in terms of the clusters depicted in our findings. This is summarized in Table III.

TABLE III

FUTURE RESEARCH DIRECTIONS

Type of convergence Research directions

Further research into the processes of IC

Industry convergence are required stemming from the propositions offered.

How does media convergence research fit into IC - a detailed look at media industry is needed.

\section{convergence}

Media and
communication

\section{Market, club, and cluster convergence}

The impact of convergence on learning and development

\section{Industrial convergence}

\section{Regulatory oversight and user adoption}

When is $\mathrm{MO}$ a replacement for $\mathrm{SC}$ ?

The number of studies is sparse on interrelationships between education and convergence.

What are the prerequisites for industrial catch-up for less industrialized nations? $\mathrm{MC}$ and the relationship studied.
SC is understudied including research on SC occurring after IC and MC.

The role of CT in DC and IC is sparse in the literature.

The international dimensions of IC are absent from the literature.

How do SC, MC, and IC impact learning and education and vice versa?

The relationship between IC and industrial catchup.

Government demand to be delineated from Further research into consumption of convergent vs. specialized technologies and products.
In industry convergence (the red cluster), we call for further research into the processes of IC and MC as highlighted in the findings. One possible avenue is to consider digital convergence (DC) studies [76], [87], [102], which may demonstrate similar pathways. Additionally, given the lack of scientific convergence as identified by Sick et al. [2], further conceptual and empirical investigation to gain an understanding of SC and its part in the systems of IC, is needed. SC may also happen as a result of other convergences as scientific convergence may occur post factum [103]. This happens when industrial developments are fast changing, for instance, the convergence of the scientific discovery of the ridesharing business has not occurred even though the ridesharing business model has facilitated disruptions in the automobile and taxi industries.

In media and communication convergence (the green cluster), future research can examine the processes and nature of convergence in the media industry in a more in-depth manner. Interestingly, although earlier research demonstrates that communication technology firms follow disparate convergence paths [94], the convergence processes of communication technology developments have not been studied in detail. Indeed, there is little research on the importance of communication technology developments in facilitating convergence in general, and IC in particular.

In market, club, and cluster convergence (the blue cluster), 
there is still limited research examining as to when MO or SC leads to convergence in general, or IC in particular. Future research can investigate the context when the process of convergence starts with MO and the context when the process of convergence begins with SC. Additionally, given that IC is dependent on the external environment [4] including changes in the international markets, further studies need to look into the context of international technology diffusion and its impact on IC. Interestingly, the internationalization factor of IC is relatively absent from the literature. Future studies, for example, can examine how industrial or technological developments affect IC in a country or a geographical region.

In the impact of convergence on learning and development (the yellow cluster), the impact of the convergent technologies on the broader education system has not been extensively explored in the literature. Arguably, there is also scope for research examining the impact of other convergences including scientific, market, and industry on the systems of education, given that most research within this cluster highlights the impacts of TC on learning and development. Future studies may also explore how the education system on the whole influences convergence or examine how educational development impacts the rate of convergence.

In relation to industrial convergence (the lilac cluster), we propose that future research can look into examining the drivers/factors that facilitate and/or inhibit countries from converging economically. In other words, there is a potential for research to examine the factors that facilitate the convergence of some emerging economies to achieve world standards or the factors that inhibit such convergence. In addition, future studies can look into the relationship between IC and industrial convergence. For example, if IC were to occur in a developing country due to factors such as supportive government policies [104], [105], does this ensure faster industrial catch-up and convergence?

Finally, for regulatory oversight and user adoption (the aqua cluster), future research can further examine the role of the government in facilitating convergence. We also suggest that in terms of user adoption, there is potential area of research to explore the consumption patterns of specialized vs convergent products and services given that there is relatively sparse literature on this (see cluster 6).

In conclusion, our scientometric review on convergence suggests the existence of six clusters of convergence research. In doing so, we have differentiated the various concepts of convergence which will help scholars interested in this field of research to use and apply these different concepts in a more consistent manner. We have also highlighted the main characteristics underpinning each of these clusters (with some examples of studies) and have suggested the directions of future studies for each of the clusters. Our systematic review further highlights that while existing literature is primarily focused on the 'driving markets' process, convergence can also be explained through the 'market-driven' process when products and services are offered to respond to market demands. The convergence pattern identified in this study hopefully serves as a preliminary start for future research examining convergence in general, and the processes of IC in particular.

\section{REFERENCES}

[1] C. S. Curran, S. Bröring, and J. Leker, "Anticipating converging industries using publicly available data," Technol. Forecast. Soc. Change, vol. 77, no. 3, pp. 385-395, 2010.

[2] G. Arrighi, B. J. Silver, and B. D. Brewer, "Industrial convergence and the persistence of the North-South income divide: A rejoinder to Firebaugh (2004)," Stud. Comp. Int. Dev., vol. 40, no. 1, pp. 83-87, 2005.

[3] N. Apergis, C. Christou, and S. M. Miller, "Country and industry convergence of equity markets: International evidence from club convergence and clustering Nicholas," North Am. J. Econ. Financ., vol. 29, pp. 36-58, 2014.

[4] N. Rosenberg, "Technological change in the machine tool industry, 1840-1910," J. Econ. Hist., vol. 23, no. 4, pp. 414-443, 1963.

[5] J. Kim, S. Kim, and C. Lee, "Anticipating technological convergence: Link prediction using Wikipedia hyperlinks," Technovation, vol. 79, no. November 2016, pp. 25-34, 2019.

[6] N. Sick, N. Preschitschek, J. Leker, and S. Bröring, “A new framework to assess industry convergence in high technology environments," Technovation, vol. 84-85, no. January 2017, pp. 48-58, 2019.

[7] J. Nightingale, 'On the definition of 'industry' and 'market,"' J. Ind. Econ., vol. 27, no. 1, pp. 31-40, 1978.

[8] S. Bröring, L. M. Cloutier, and J. Leker, "The front end of innovation in an era of industry convergence: Evidence from nutraceuticals and functional foods," R\&D Manag., vol. 36, no. 5, pp. 487-498, 2006.

[9] N. Kim, H. Lee, W. Kim, H. Lee, and J. H. Suh, "Dynamic patterns of industry convergence: Evidence from a large amount of unstructured data," Res. Policy, vol. 44, no. 9, pp. 1734-1748, 2015.

[10] C. S. Curran and J. Leker, "Patent indicators for monitoring convergence - examples from NFF and ICT," Technol. Forecast. Soc. Change, vol. 78, no. 2, pp. 256-273, 2011.

[11] N. Preschitschek, H. Niemann, J. Leker, and M. G. Moehrle, "Anticipating industry convergence:

Semantic analyses vs IPC co-classification analyses of patents," Foresight, vol. 15, no. 6, pp. 446-464, 2013.

[12] A. Gambardella and S. Torrisi, "Does technological convergence imply convergence in markets? Evidence from the electronics industry," Res. Policy, vol. 27, no. 5, pp. 445-463, 1998.

[13] G. Duysters and J. Hagedoorn, "Technological convergence in the IT industry: The role of strategic technology alliances and technological competencies," Int. J. Econ. Bus., vol. 21, no. 1, pp. 355-368, 1998.

[14] J. Kim and S. Lee, "Forecasting and identifying multitechnology convergence based on patent data: The case of IT and BT industries in 2020," Scientometrics, vol. 111, no. 1, pp. 47-65, 2017.

[15] W. Xing, X. Ye, and L. Kui, "Measuring convergence 
of Chinas ICT industry: An input-output analysis," Telecomm. Policy, vol. 35, no. 4, pp. 301-313, 2011.

[16] F. Hacklin, C. Marxt, and F. Fahrni, "Coevolutionary cycles of convergence: An extrapolation from the ICT industry," Technol. Forecast. Soc. Change, vol. 76, no. 6, pp. 723-736, 2009.

[17] O. Westlund, "Mobile news: A review and model of journalism in an age of mobile media," Digit.

Journal., vol. 1, no. 1, pp. 6-26, 2013.

[18] R. Salaverria, "Technological convergence in the media: Challenges for journalism," Tripodos, no. 23, pp. 31-47, 2008.

[19] C. Wernz, P. T. Wernz, and K. Phusavat, "Service convergence and service integration in medical tourism," Ind. Manag. Data Syst., vol. 114, no. 7, pp. 1094-1106, 2014.

[20] W. Shen, B. Liu-Lastres, L. Pennington-Gray, X. Hu, and J. Liu, "Industry convergence in rural tourism development: A China-featured term or a new initiative?," Curr. Issues Tour., vol. 22, no. 20, pp. 2453-2457, 2019.

[21] W. J. Lee, W. K. Lee, and S. Y. Sohn, "Patent network analysis and quadratic assignment procedures to identify the convergence of robot technologies," PLoS One, vol. 11, no. 10, pp. 1-16, 2016.

[22] T. Kose and I. Sakata, "Identifying technology convergence in the field of robotics research," Technol. Forecast. Soc. Change, vol. 146, no. August 2018, pp. 751-766, 2019.

[23] P. S. Heo and D. H. Lee, "Evolution patterns and network structural characteristics of industry convergence," Struct. Chang. Econ. Dyn., vol. 51, pp. 405-426, 2019.

[24] R. Galli, "Is there long run industrial convergence in Europe?," Int. Rev. Appl. Econ., vol. 11, no. 3, pp. 333-368, 1997.

[25] G. Arrighi, B. J. Silver, and B. D. Brewer, "Industrial convergence, globalization, and the persistence of the North-South divide," Stud. Comp. Int. Dev., vol. 38, no. 1, pp. 3-31, 2003.

[26] F. Lemoine, S. Poncet, and D. Ünal, "Spatial rebalancing and industrial convergence in China," China Econ. Rev., vol. 34, pp. 39-63, 2015.

[27] Y. Geum, M. S. Kim, and S. Lee, "How industrial convergence happens: A taxonomical approach based on empirical evidences," Technol. Forecast. Soc.

Change, vol. 107, pp. 112-120, 2016.

[28] M. Karvonen and T. Kässi, "Patent citations as a tool for analysing the early stages of convergence," Technol. Forecast. Soc. Change, vol. 80, no. 6, pp. 1094-1107, 2013.

[29] B. Jaworski, A. K. Kohli, and A. Sahay, "Marketdriven versus driving markets," J. Acad. Mark. Sci., vol. 28, no. 1, pp. 45-54, 2000.

[30] N. Kumar, L. Scheer, and P. Kotler, "From market driven to market driving," Eur. Manag. J., vol. 18, no. 2, pp. 129-142, 2000.

[31] A. Klarin, "Mapping product and service innovation: A bibliometric analysis and a typology," Technol. Forecast. Soc. Change, vol. 149, no. December, p.
119776, 2019.

[32] R. G. Cooper, "New products - what separates the winners from the losers and what drives success," in The PDMA Handbook of New Product Development, Third., K. B. Kahn, S. E. Kay, R. J. Slotegraaf, and S. Uban, Eds. New Jersey: John Wiley \& Sons, 2013.

[33] S. S. Ansari and P. Krop, "Incumbent performance in the face of a radical innovation: Towards a framework for incumbent challenger dynamics," Res. Policy, vol. 42, no. 2, p. 577, 2013.

[34] S. Bröring, "Developing innovation strategies for convergence - Is 'open innovation' imperative?," Int. J. Technol. Manag., vol. 49, no. 1-3, pp. 272-294, 2010.

[35] N. Cortez, "International health care convergence: The benefits and burdens of market-driven

standardization," Wisconsin Int. Law J., vol. 26, no. 3, pp. 646-703, 2008.

[36] M. Petticrew and H. Roberts, Systematic Reviews in the Social Sciences: A Practical Guide. Oxford: Blackwell Publishing, 2006.

[37] D. Tranfield, D. Denyer, and P. Smart, "Towards a methodology for developing evidence-informed management knowledge by means of systematic review," Br. J. Manag., vol. 14, no. 3, pp. 207-222, 2003.

[38] I. Zupic and T. Čater, "Bibliometric methods in management and organization," Organ. Res. Methods, vol. 18, no. 3, pp. 429-472, 2015.

[39] D. Nazarov and A. Klarin, "Taxonomy of Industry 4.0 research: Mapping scholarship and industry insights," Syst. Res. Behav. Sci., vol. 37, no. 4, pp. 535-556, 2020.

[40] P. Korom, "A bibliometric visualization of the economics and sociology of wealth inequality: A world apart?," Scientometrics, vol. 118, no. 3, pp. 849-868, 2019.

[41] N. J. van Eck and L. Waltman, "Software survey: VOSviewer, a computer program for bibliometric mapping," Scientometrics, vol. 84, no. 2, pp. 523-538, 2010.

[42] N. J. van Eck and L. Waltman, "Visualizing bibliometric networks," in Measuring Scholarly Impact, Y. Ding, R. Rousseu, and D. Wolfram, Eds. Springer, Cham, 2014, pp. 285-320.

[43] A. Klarin, B. Inkizhinov, D. Nazarov, and E. Gorenskaia, "International business education: What we know and what we have yet to develop," Int. Bus. Rev., no. In press, p. 101833, 2021.

[44] C. D. Mulrow, "Systematic Reviews : Rationale for systematic reviews An efficient scientific technique," Br. Med. J., vol. 309, no. September, pp. 597-599, 1994.

[45] M. J. Grant and A. Booth, "A typology of reviews: An analysis of 14 review types and associated methodologies," Health Info. Libr. J., vol. 26, no. 2, pp. 91-108, 2009.

[46] J. S. Justeson and S. M. Katz, "Technical terminology: Some linguistic properties and an algorithm for identification in text," Nat. Lang. Eng., vol. 1, no. 1, 
pp. 9-27, Mar. 1995.

[47] M. M. Crossan and M. Apaydin, "A multidimensional framework of organizational innovation: A systematic review of the literature," J. Manag. Stud., vol. 47, no. 6, pp. 1154-1191, 2010.

[48] P. M. Podsakoff, S. B. MacKenzie, N. P. Podsakoff, and D. G. Bachrach, "Scholarly influence in the field of management: A bibliometric analysis of the determinants of university and author impact in the management literature in the past quarter century," $J$. Manage., vol. 34, no. 4, pp. 641-720, 2008.

[49] E. S. Vieira and J. A. N. F. Gomes, "A comparison of Scopus and Web of Science for a typical university," Scientometrics, vol. 81, no. 2, pp. 587-600, 2009.

[50] I. Rafols, L. Leydesdorff, A. O'Hare, P. Nightingale, and A. Stirling, "How journal rankings can suppress interdisciplinary research: A comparison between Innovation Studies and Business \& Management," Res. Policy, vol. 41, no. 7, pp. 1262-1282, 2012.

[51] A. Klarin and Y. Suseno, "A state-of-the-art review of the sharing economy: Scientometric mapping of the scholarship,” J. Bus. Res., vol. 126, pp. 250-262, 2021.

[52] B. Golembiewski, N. Sick, and S. Bröring, "Patterns of convergence within the emerging bioeconomy The case of the agricultural and energy sector," Int. J. Innov. Technol. Manag., vol. 12, no. 3, 2015.

[53] C. H. Song, D. Elvers, and J. Leker, "Anticipation of converging technology areas — A refined approach for the identification of attractive fields of innovation," Technol. Forecast. Soc. Change, vol. 116, pp. 98-115, 2017.

[54] B. W. Wirtz, "Reconfiguration of value chains in converging media and communications markets," Long Range Plann., vol. 34, no. 4, pp. 489-506, 2001.

[55] A. Christin, "Counting clicks: Quantification and variation in web journalism in the United States and France," Am. J. Sociol., vol. 123, no. 5, pp. 13821415, 2018.

[56] L. Humphreys, T. Von Pape, and V. Karnowski, "Evolving mobile media: Uses and conceptualizations of the mobile internet," J. Comput. Commun., vol. 18, no. 4, pp. 491-507, 2013.

[57] A. J. Flanagin, "Online social influence and the convergence of mass and interpersonal communication," Hum. Commun. Res., vol. 43, no. 4, pp. 450-463, 2017.

[58] C. Kerr, J. T. Dunlop, F. Harbison, and C. A. Myers, Industrialism and Industrial Man. New York: Oxford University Press, 1960.

[59] X. X. . Sala-i-Martin, "The classical approach to convergence analysis," Econ. J., vol. 106, no. 437, pp. 1019-1036, 1996.

[60] P. C. B. Phillips and D. Sul, "Transition modeling and econometric convergence tests," Econometrica, vol. 75, no. 6, pp. 1771-1855, 2007.

[61] J. Zhang, P. McBurney, and K. Musial, "Convergence of trading strategies in continuous double auction markets with boundedly-rational networked traders," Rev. Quant. Financ. Account., vol. 50, no. 1, pp. 301-
$352,2018$.

[62] N. Mylonidis and C. Kollias, "Dynamic European stock market convergence: Evidence from rolling cointegration analysis in the first euro-decade," $J$. Bank. Financ., vol. 34, no. 9, pp. 2056-2064, 2010.

[63] G. M. Caporale, B. Erdogan, and V. Kuzin, "Testing stock market convergence: A non-linear factor approach," Empirica, vol. 42, no. 3, pp. 481-498, 2015.

[64] M. S. Chien, C. C. Lee, T. C. Hu, and H. T. Hu, "Dynamic Asian stock market convergence: Evidence from dynamic cointegration analysis among China and ASEAN-5," Econ. Model., vol. 51, pp. 84-98, 2015.

[65] C. Lu, J. Qiao, and J. Chang, "Herfindahl-Hirschman Index based performance analysis on the convergence development," Cluster Comput., vol. 20, no. 1, pp. 121-129, 2017.

[66] M. Monfort, J. C. Cuestas, and J. Ordóñez, "Real convergence in Europe: A cluster analysis," Econ. Model., vol. 33, pp. 689-694, 2013.

[67] C. J. Yen and M. Abdous, "A study of the predictive relationships between faculty engagement, learner satisfaction and outcomes in multiple learning delivery modes," Int. J. Distance Educ. Technol., vol. 10, no. 1, pp. 74-87, 2012.

[68] J. M. Vaterlaus, L. A. Spruance, K. Frantz, and J. S. Kruger, "College student television binge watching: Conceptualization, gratifications, and perceived consequences," Soc. Sci. J., vol. 56, no. 4, pp. 470479, 2018.

[69] E. Hernández-Merayo, M. C. Vílchez-Robles, and J. B. Martínez-Rodríguez, "Interactive youth and civic cultures: The educational, mediatic and political meaning of the 15M," Comunicar, vol. 20, no. 40, pp. 59-67, 2013.

[70] F. Karakas and A. Manisaligil, "Reorienting selfdirected learning for the creative digital era," Eur. J. Train. Dev., vol. 36, no. 7, pp. 712-731, 2012.

[71] B. Thornhill-Miller and J.-M. Dupont, "Virtual reality and the enhancement of creativity and innovation: Under recognized potential among converging technologies?," J. Cogn. Educ. Psychol., vol. 15, no. 1, pp. 102-121, 2016.

[72] B. Fainholc, "Teaching and learning in the knowledge society," Encount. Theory Hist. Educ., vol. 6, pp. 87105, 2008.

[73] G. Cameron, J. Proudman, and S. Redding, "Technological convergence, R\&D, trade and productivity growth," Eur. Econ. Rev., vol. 49, no. 3, pp. 775-807, 2005.

[74] S. Dowrick, "Classical and technological convergence: Beyond the Solow-Swan growth model," Oxf. Econ. Pap., vol. 54, no. 3, pp. 369-385, 2002.

[75] C. Liu, "Examining China's triple-network convergence plan: Regulatory challenges and policy recommendations," Gov. Inf. Q., vol. 30, no. 1, pp. 45-55, 2013.

[76] H. U. Steen, "Limits to the regulatory state in the rulemaking of digital convergence: A case study of mobile 
TV standards governance in the European Union and China," Technol. Anal. Strateg. Manag., vol. 23, no. 7, pp. 759-772, 2011.

[77] C. R. Blackman, "Convergence between telecommunications and other media: How should regulation adapt?," Telecomm. Policy, vol. 22, no. 3, pp. 163-170, 1998.

[78] Y. Yasunaga, M. Watanabe, and M. Korenaga, "Application of technology roadmaps to governmental innovation policy for promoting technology convergence," Technol. Forecast. Soc. Change, vol. 76, no. 1, pp. 61-79, 2009.

[79] C. McLeish and P. Nightingale, "Biosecurity, bioterrorism and the governance of science: The increasing convergence of science and security policy," Res. Policy, vol. 36, no. 10, pp. 1635-1654, 2007.

[80] J. Schmidt, R. Makadok, and T. Keil, "Customerspecific synergies and market convergence," Strateg. Manag. J., vol. 37, no. 5, pp. 870-895, 2016.

[81] F. Ter Hofstede, M. Wedel, and J. B. E. M. Steenkamp, "Identifying spatial segments in international markets," Mark. Sci., vol. 21, no. 2, pp. 160-177, 2002.

[82] R. S. Achrol and P. Kotler, "Marketing in the Network Economy," J. Mark., vol. 63, no. 4, pp. 146-163, 1999.

[83] Y. Z. Wei, L. Moreau, and N. R. Jennings, "Learning users' interests by quality classification in marketbased recommender systems," IEEE Trans. Knowl. Data Eng., vol. 17, no. 12, pp. 1678-1688, 2005.

[84] J. K. Han, S. W. Chung, and Y. S. Sohn, “Technology convergence: When do consumers prefer converged products to dedicated products?," J. Mark., vol. 73, no. 4, pp. 97-108, 2009.

[85] D. H. Shin, "Determinants of customer acceptance of multi-service network: An implication for IP-based technologies," Inf. Manag., vol. 46, no. 1, pp. 16-22, 2009.

[86] E. J. M. Arruda-Filho, J. A. Cabusas, and N. Dholakia, "Social behavior and brand devotion among iPhone innovators," Int. J. Inf. Manage., vol. 30, no. 6, pp. 475-480, 2010.

[87] D. B. Yoffie, "Competing in the age of digital convergence,” Calif. Manage. Rev., no. 4, pp. 31-53, 1996.

[88] H. Jenkins, Convergence Culture: Where Old and New Media Collide. New York: New York University Press, 2006.

[89] E. G. Bormann, "The symbolic convergence theory of communication: Applications and implications for teachers and consultants," J. Appl. Commun. Res., vol. 10, no. 1, pp. 50-61, 1982.

[90] N. Stieglitz, "Industry dynamics and types of market convergence: The evolution of the handheld computers market in the 1990s and beyond," DRUID Summer Conf. Copenhagen, no. June, pp. 1-41, 2002.

[91] W. G. Peacock, G. A. Hoover, and C. D. Killian, "Divergence and convergence in international development: A decomposition analysis of inequality in the world system," Am. Sociol. Rev., vol. 53, no. 6, pp. 838-852, 1988.

[92] N. Apergis, C. Christou, and C. Hassapis,

"Convergence in public expenditures across EU countries: Evidence from club convergence," Econ. Financ. Res., vol. 1, no. 1, pp. 45-59, 2013.

[93] R. J. Neuwirth, "Global market integration and the creative economy: The paradox of industry convergence and regulatory divergence," J. Int. Econ. Law, vol. 18, no. 1, pp. 21-50, 2015.

[94] I. de S. Pool, On Free Speech in an Electronic Age: Technologies of Freedom. Cambridge: Harvard University Press, 1983.

[95] K. Rabah, "Convergence of AI, IoT, big data and blockchain: A review," Int. J. Intell. Syst., vol. 1, no. 1, pp. 1-18, 2018.

[96] M. Li, A. Hsiao, E. J. Ma, and S.-J. Li, "Hotel service convergence innovation," J. Glob. Sch. Mark. Sci., vol. 00, no. 00, pp. 1-17, 2021.

[97] J. Krämer and M. Wohlfarth, "Market power, regulatory convergence, and the role of data in digital markets," Telecomm. Policy, vol. 42, no. 2, pp. 154$171,2018$.

[98] X. Wan, J. Cenamor, and J. Chen, "Exploring performance determinants of China's cable operators and OTT service providers in the era of digital convergence-From the perspective of an industry platform," Sustain., vol. 9, no. 12, 2017.

[99] D. Holbrook, "Controlling contamination: The origins of clean room technology," Hist. Technol., vol. 25, no. 3, pp. 173-191, 2009.

[100] S. Shaheen, D. Sperling, and C. Wagner, "Carsharing and partnership management: An international perspective," Transp. Res. Rec., no. 1666, pp. 118124, 1999.

[101] M. Juschten, T. Ohnmacht, V. T. Thao, R. Gerike, and R. Hössinger, "Carsharing in Switzerland: Identifying new markets by predicting membership based on data on supply and demand," Transportation (Amst)., vol. 46, no. 4, pp. 1171-1194, 2019.

[102] S. M. Greenstein and T. Khanna, "What does it mean for industries to converge?," in Competing in the Age of Digital Convergence, D. B. Yoffie, Ed. Boston: Harvard Business School Press, 1997, pp. 201-226.

[103] A. Chakrabarti, "Role of universities in product development process: Strategic considerations for telecommunications industry," in Handbook of Product and Service Development in Communication and Information Technology, T. O. Korhonen and A. Ainamo, Eds. Springer Science \& Business Media, 2007, pp. 235-254.

[104] J.-H. Wang, "From technological catch-up to innovation-based economic growth: South Korea and Taiwan compared," J. Dev. Stud., vol. 43, no. 6, pp. 1084-1104, Aug. 2007.

[105] H.-J. Chang, "Breaking the mould: An institutionalist political economy alternative to the neoliberal theory of the market and the state," J. Dev. Areas, vol. 26, no. 5, pp. 539-559, 2002. 